Research Article

\title{
Genotoxic and histotoxic effects of air pollutants at a benzene station on albino rats
}

\author{
Mohamed Abousalem $^{1}$, Amer Elgerwi ${ }^{2}$, Abdel Baset El-Mashad ${ }^{3}$
}

\begin{abstract}
${ }^{1}$ Department of Forensic
Medicine and Toxicology, Benha

University, Moshtohor-13736,

Egypt,

${ }^{2}$ Department of Pharmacology,

Toxicology and Forensic

Medicine, Tripoli University,

Tripoli-13662, Libya,

${ }^{3}$ Department of Pathology, Benha

University, Moshtohor-13736,

Egypt
\end{abstract}

Received: 2 December 2013

Accepted: 15 December 2013

\section{*Correspondence to:}

Dr. Mohamed Abousalem,

Email: abosalem_m@yahoo.com

(C) 2014 Abousalem $\mathrm{M}$ et al. This

is an open-access article

distributed under the terms of the

Creative Commons Attribution

Non-Commercial License, which permits unrestricted non-

commercial use, distribution, and reproduction in any medium, provided the original work is properly cited.

\begin{abstract}
Background: This study was designed to explore the hazardous effects of occupational exposure to air pollutants arising from benzene stations.

Methods: A total of 48 albino rats were divided into three groups each of sixteen animals. Groups-I and II were kept at a benzene station for 60 and 120 days, respectively; while group-III was kept as a control under normal laboratory conditions. At the end of the experiment, animals were sacrificed and bone marrow samples were taken to investigate the effect of air pollutants at a benzene station on chromosomal aberrations and micronuclei formation. Tissue samples were also picked out to evaluate histotoxic effects of these air pollutants.

Results: Results indicated pronounced time-dependent effects because of the work place pollutants. Genetic examination revealed higher frequency of chromosomal aberrations and elevated mitotic index after exposure to air pollutants. Micronuclei formation also increased either in polychromatic or normochromatic erythrocyte due to air pollutants. Histopathological examination revealed congestion of the pulmonary blood vessels with pulmonary edema. Bronchial hyperplasia and metaplasia were also seen in late stage of exposure. The liver showed degenerative changes or even necrosis of hepatocytes, while the kidneys showed congestion of the renal blood vessels and glomerular tufts. Hyalinization of the glomeruli was also detected. The heart showed various mononuclear infiltration and the testes showed degenerative changes of seminiferous tubules. Spleen showed hemosiderosis while testes showed degenerative changes of seminiferous tubules.

Conclusions: The findings of the present study indicated that benzene exposure may lead to toxic effects including, genotoxicities and histotoxicities. In order to minimize the predicted toxic effect of occupational exposure to benzene the strict protective measures should be put in consideration.
\end{abstract}

Keywords: Benzene, Bone marrow, Pollutants, Genotoxic, Histotoxic, Kidneys, Liver, Lungs

\section{INTRODUCTION}

Occupational toxicity due to the effect of pollutants at work place is of basic importance because of the time factor that lasts about 8 hours daily.

Benzene is a heavily used industrial chemical, petroleumby-product, an additive in unleaded gas, and a ubiquitous environmental pollutant. It is classified as a "Known" carcinogen "Category A" under the risk assessment Guidelines of 1986. Many experimental animal studies, both inhalation and oral, also support the evidence that exposure to benzene increases the risk of cancer in multiple organ system including the hematopoietic system, oral and nasal cavities, liver, fore stomach, preputial gland, lung, ovary and mammary gland. ${ }^{1}$ Alteration in bone marrow and neutropenia in patients due to chronic exposure to organic solvents (benzene) was reported. ${ }^{2}$ Benzene and its metabolites (phenol, hydroquinone and catechol) cause myeloclastogenic effects such as micronuclei, chromosomal aberrations and sister chromatide exchange. ${ }^{3}$ Benzene elicited a significant increase in the frequency of micronucleated polychromatic erythrocyte in fetal liver blood cells, 
peripheral blood cells and maternal bone marrow cells, where it had a moderate transplacental clastogenic effect. ${ }^{4}$ The distribution of the break-point in the karyotypes of workers occupationally exposed to benzene was studied by $^{5}$ where a significant increase in chromosome aberrations was observed. Similarly, an increase in structural and numerical chromosomal aberrations in lymphocytes of benzene exposed workers was recorded. ${ }^{6}$ The interaction of benzene metabolites (phenol and hydroquinone) resulted in a marked increase in micronuclei $(\mathrm{MN})$ formed in bone marrow erythrocytes which was significantly greater than that observed with individual metabolites.

Concerning pathological effects of benzene, exposure of mice and rats to the vapour of benzene and some other chemicals produced degenerative changes in the parenchymatous organs in the form of centrilobular necrosis in the liver and fatty change of hepatocytes besides necrosis of the tubular epithelium of the kidney. ${ }^{8-}$

${ }^{10}$ Similarly, ${ }^{11}$ mentioned that the exposure to vapour of benzene produced necrosis of liver and haemorrhage.

This work designed to investigate the different genotoxic and pathological hazards predicted to affect certain group of individuals occupationally exposed to air pollutants (arising at a benzene station) for different periods at work place environment. The novelty of the work is its adoption in the Egyptian environment because of unavailability of such information. We used laboratory animals (albino rats) allocated in the same work area for different periods after which these animals were subjected to detailed toxicopathological investigations.

\section{METHODS}

\section{Animal grouping and exposure}

The study was carried out on 48 mature wister rats of both sexes weighed 120-140 grams body weight at the start of the experiment. These animals were divided into three groups each of 16 rats. The first and the second groups were kept at a benzene station for 60 and 120 days, respectively, while the third group was kept as a control in our laboratory animal unit. The basis of 60 and 120 days was designed to investigate the effect of time exposure to the benzene-derived air pollutants whether it is self-limiting or may increase by time. The basis of 24 hour exposure/day was designed to simulate the actual life of most of workers at Egyptian benzene stations. At the benzene station, animals were exposed to air pollutants particularly volatile organic compounds, e.g., benzene, kerosin, different oils etc. All animals were offered balanced diet and water ad libitum.

\section{Sampling}

At the end of the experimental periods, animals were sacrificed and bone marrow samples were collected from the femur bones for investigating chromosomal aberrations and micronuclei formation. Myeloclastogenic effects including chromosomal investigations and micronuclei formation either in polychroamtic erythrocytes (PCE) or in normochromatic erythrocyte (NCE) were carried out according to ${ }^{12,13}$ respectively.

For histopathological examination, specimens were taken from liver, kidneys, lungs and heart and fixed in $10 \%$ buffered neutral formalin solution. After proper fixation, the specimens were prepared, sectioned at $5 \mu \mathrm{m}$ thickness and stained by hematoxylene and eosine. ${ }^{14}$ In addition, Prussian blue stain was used for hemosiderin pigments. ${ }^{15}$ Eight rats from the control group were sacrificed after 60 days exposure, while the remaining 8 were sacrificed after 120 days to make correspondence with the test groups regarding time and age.

\section{RESULTS}

\section{Genotoxic findings}

The clastogenic effects induced in exposed animals was shown in (Table 1 and Table 2) and (figures 1-6). Table 1 and Figs 1, 2, $3 \& 4$ shows higher frequency of chromsomal aberrations and elevated mitotic index after exposure to air pollutants. Table 2 and Figs 5 \& 6 show that micronuclei formation increases either in polychromatic or normochromatic erythrocyte due to air pollutants.

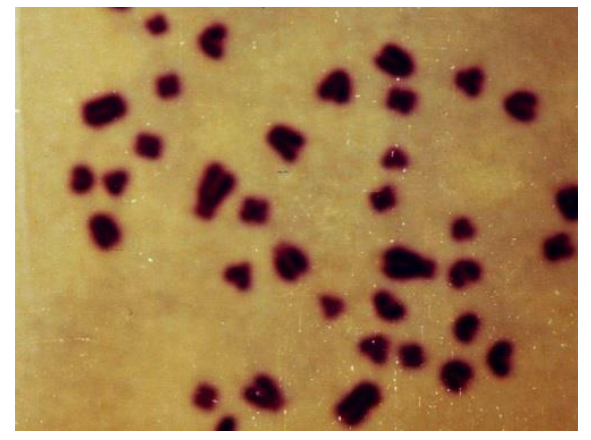

Figure 1: Metaphase spread of albino rat kept as a control showing normal chromosomal pattern $(2 \mathrm{n}=$ 42) (x 1000).

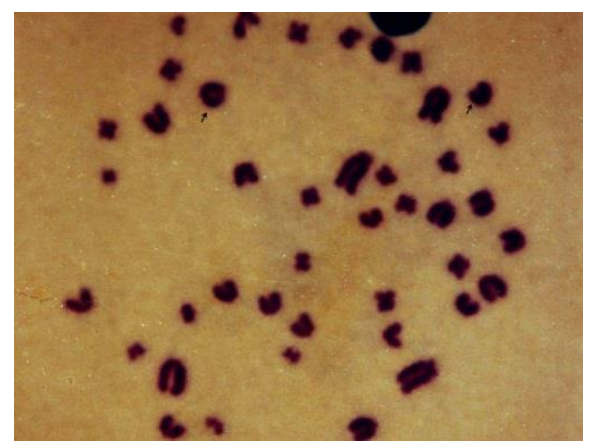

Figure 2: Metaphase spread of albino rat exposed to air pollutants at a benzene station for 60 days showing ring chromosome $(x$ 1000). 


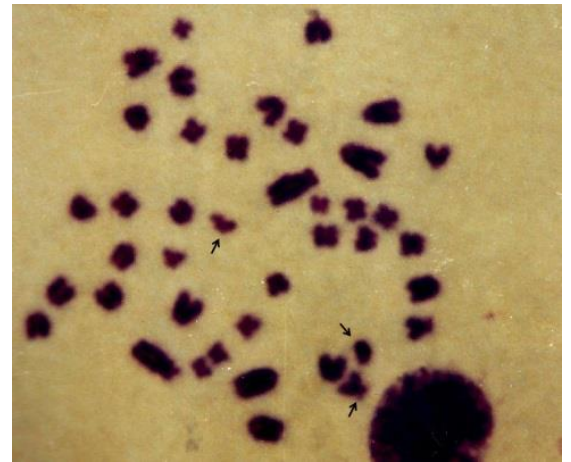

Figure 3: Metaphase of albino rat exposed to air pollutants at a benzene station for 120 days showing centromenic attenuation. (x 1000).

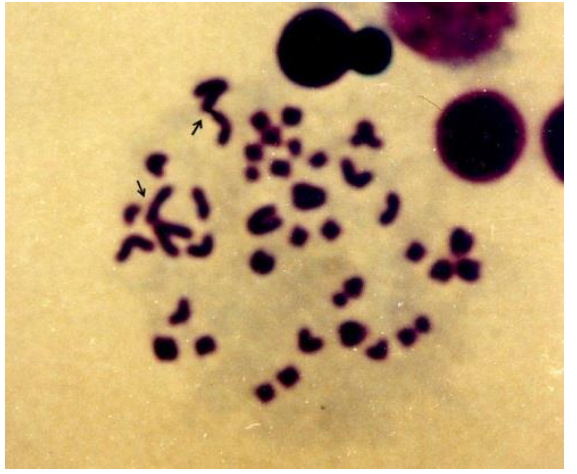

Figure 4: Metaphase spread of albino rat exposed to air pollutant at a benzene station for 120 days showing end to end association (x 1000).

Table 1: Frequency of chromosomal aberrations in examined metaphase spread of bone marrow obtained from albino rats exposed to air pollutants arising from benzene station for 60 and 120 days versus control.

\begin{tabular}{|c|c|c|c|c|c|c|c|c|c|c|c|c|c|c|}
\hline & $\begin{array}{l}\text { Total } \\
\text { examin- } \\
\text { ed } \\
\text { Metap-- } \\
\text { hase } \\
\text { spread } \\
\text { (M.S.) }\end{array}$ & $\begin{array}{l}\% \\
\text { M.S. } \\
\text { chro-- } \\
\text { mos- } \\
\text { omal } \\
\text { aberra } \\
\text { tion }\end{array}$ & & & & & Numb & recor & chromos & I aberrat & & & & \\
\hline & & & Gap & $\begin{array}{l}\text { Frag- } \\
\text { ment }\end{array}$ & Break & $\begin{array}{l}\text { Dele- } \\
\text { tion }\end{array}$ & Sticky & Ring & $\begin{array}{l}\text { Asso- } \\
\text { ciation }\end{array}$ & $\begin{array}{l}\text { Attenu- } \\
\text { ation }\end{array}$ & $\begin{array}{l}\text { Polyp- } \\
\text { loidy }\end{array}$ & Total & $\%$ & Mitotic index \\
\hline $\begin{array}{l}\text { Unexpos- } \\
\text { ed } \\
\text { animals }\end{array}$ & 800 & 5 & 13 & 1.0 & 5 & 3.0 & 1.0 & 6 & 17 & 15 & 3.0 & 64 & 8 & $1.14 \pm 0.68$ \\
\hline $\begin{array}{l}\text { Animals } \\
\text { exposed } \\
\text { for } 60 \\
\text { days }\end{array}$ & 800 & 15 & 21 & 3.0 & 15 & 23 & 17 & 9 & 23 & 17 & 16 & 144 & 18 & $\begin{array}{l}1.74 \pm 0.93 \\
\text { n.s. }\end{array}$ \\
\hline $\begin{array}{l}\text { Animals } \\
\text { exposed } \\
\text { for } 120 \\
\text { days }\end{array}$ & 800 & 22 & 22 & 17 & 16 & 25 & 31 & 25 & 30 & 25 & 17 & 208 & 26 & $2.73 \pm 1.46^{*}$ \\
\hline
\end{tabular}

Table 2: Frequency of micromoleculei formation in polychromatic and normochromatic erythrocytes obtained from bone marrow of albino rats exposed to air pollutants arising from benzene station for 60 and 120 days versus control.

\begin{tabular}{|c|c|c|c|c|c|c|c|c|}
\hline & \multicolumn{3}{|c|}{ Polychromatic erythrocyte (PCE) } & \multicolumn{5}{|c|}{ Normochromatic erythrocyte (NCE) } \\
\hline & $\begin{array}{l}\text { Total } \\
\text { examined } \\
\text { cells }\end{array}$ & $\begin{array}{l}\text { Normal } \\
\text { cells }\end{array}$ & $\begin{array}{l}\text { Total } \\
\text { micronucleated } \\
\text { cells }\end{array}$ & $\%$ & $\begin{array}{l}\text { Total } \\
\text { examined } \\
\text { cells }\end{array}$ & $\begin{array}{l}\text { Normal } \\
\text { cells }\end{array}$ & $\begin{array}{l}\text { Total } \\
\text { micronucleated } \\
\text { cells }\end{array}$ & $\%$ \\
\hline $\begin{array}{l}\text { Animals exposed } \\
\text { for } 60 \text { days }\end{array}$ & 800 & 782 & 18 & 2.25 & 800 & 7.81 & 19 & 2.38 \\
\hline
\end{tabular}




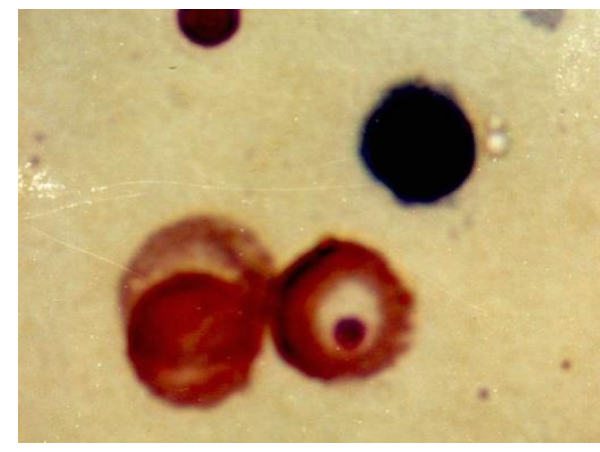

Figure 5: Bone marrow smear from albino rat exposed to air pollutant at a benzene statio for 60 days showing micronucleus formation in normochromatic erythrocyte (NCE). (x 1000).

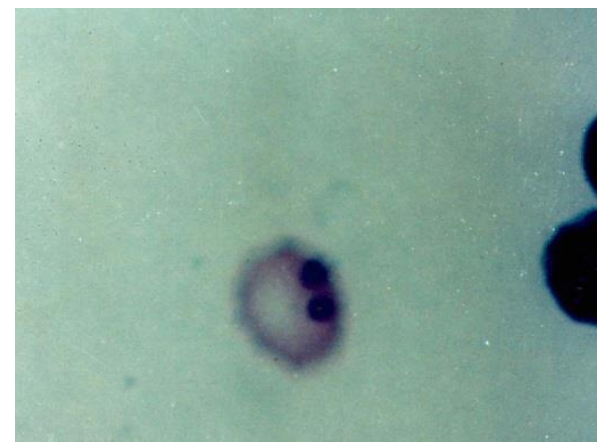

Figure 6: Bone marrow smear from albino rat exposed to air pollutant at a benzene station for 120 days showing two micronucleus formations in normochromatic erythrocyte (NCE) (x 1000).

\section{Histopathological findings}

Macroscopically, the lungs showed presence of multiple consolidated areas brownish in colour. Meanwhile, some cases showed the presence of pale coloured areas elevated above the lung surface when cutting, scanty amount of exudate come out. Microscopically, congestion of the pulmonary blood vessels and interalveolar blood capillaries was prominent. Perivascular mononuclear infiltration and perivascular edema were also detected. The alveoli showed presence of homogenous structure less faint eosinophilic substances (Figure 7). The bronchioles showed hyperplasia of their lining epithelium together with the presence of granular eosinophilic substances in their luminae (Figure 8). Moreover, some of these bronchioles showed metaplasia of their lining epithelium to stratified squamous type (Figure 9). Peribronchial mononuclear infiltration was also detected.

Macroscopically, the liver showed congestion with presence of petechiae on its cut surface. Grayish white foci were also detected. Microscopically, congestion of the central veins and hepatic sinusoids together with perivascular mononuclear infiltration were the predominant findings in all examined cases. The hepatocytes suffered from degenerative changes in the form of vacuolar and hydropic degeneration (Figure 10). Focal areas of necrosis infiltrated with mononuclear cells were observed (Figure 11). The portal areas showed mild mononuclear infiltration and periducteal fibrous tissue proliferation.

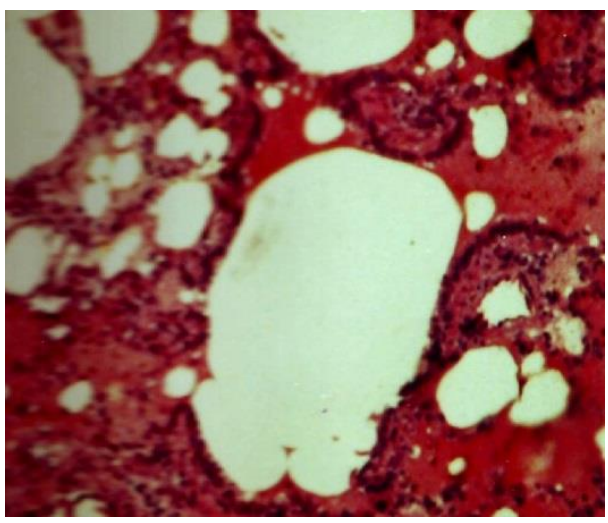

Figure 7: Lung showing structural finely eosinophilic substances in alveolar luminae (H\&E x 200).

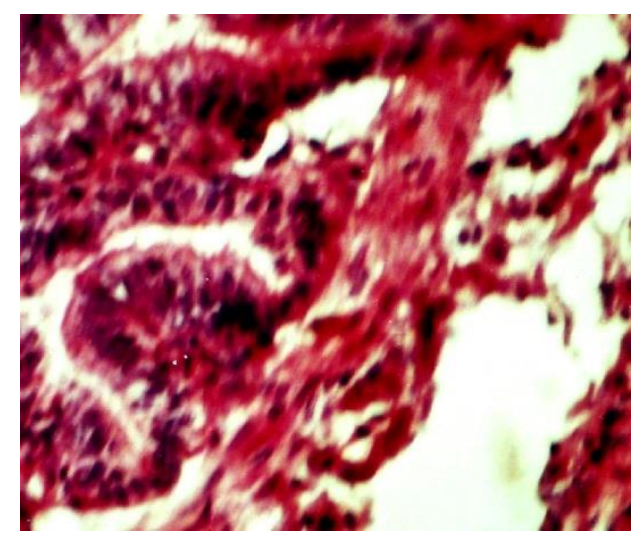

Figure 8: Lung showing hyperplasia of the bronchial epithelium with the presence of emphysematous areas (H\&E x 300).

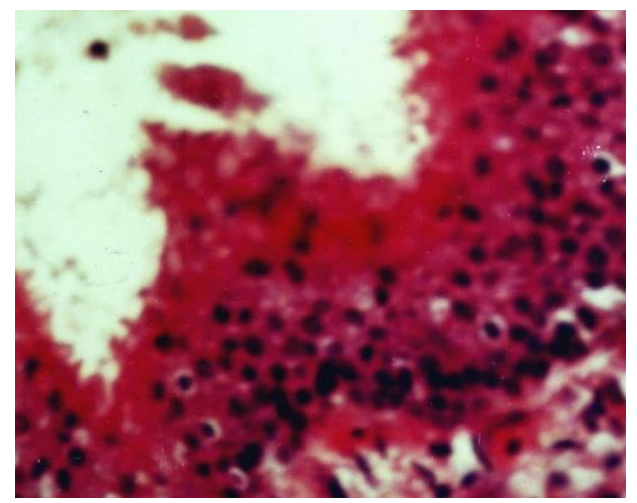

Figure 9: Lung showing metaplasia of the bronchial epithelium to stratified squamous epithelium (H\&E $x$ 630). 


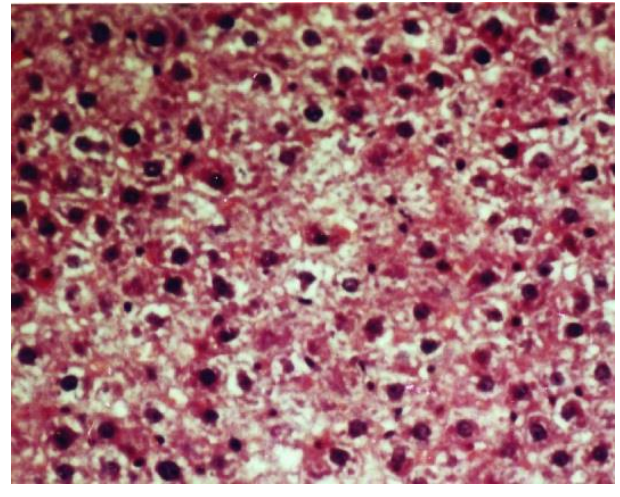

Figure 10: Liver showing hydropic degeneration of hepatocytes. (H\&E x 200).

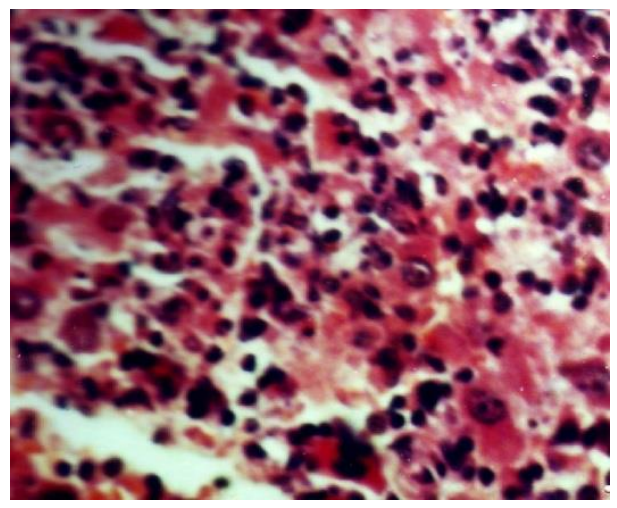

Figure 11: Liver showing focal area of necrosis manifested by degenerated hepatocytes and mononuclear infiltration (H\&E x 300).

Macroscopically, the kidneys showed congestion with the presence of petechiae on their cutting surface. Some examined kidneys showed paraboiled appearance with presence of grayish white foci on its cut-surface. Microscopically, congestion of renal blood vessels and intertubular blood capillaries was prominent. Perivascular hemorrhages were also seen. The renal tubules exhibited degenerative changes in the form of cloudy swelling in which the renal tubules showed more granular and eosinophilic cytoplasm with a narrow lumen (Figure 12). Hyaline casts were also detected in the renal tubules of the medulla. The glomeruli showed congestion of the glomerular tuft with presence of eosinophilic granular substances in the Bowman's space (Figure 13). Moreover, complete halinization of some of glomerular tuft were also observed.

Macroscopically, the heart showed focal intramuscular mononuclear infiltration (Figure 14). The myocardial muscles showing hyalinization areas. Microscopically, the spleen showed diffuse hemosiderin pigments in the form of amorphous golden yellow coloured pigments which take bluish colouration by Prussian blue stain were seen in most examined cases (Figure 15).

The testes showed mild degenerative changes of seminiferous tubules with degeneration of sperms.
Moreover, intratubular edema with the presence of pale eosinophilic substances in the tubular luminae were also detected (Figure 16).

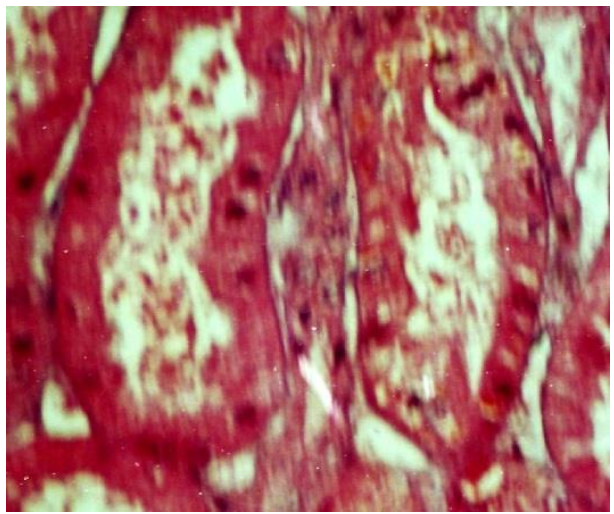

Figure 12: Kidney showing cloudy swelling of the renal tubules with the presence of glomerular eosinophilic substances in the tubular luminae (H\&E $\mathrm{x}$ 400).

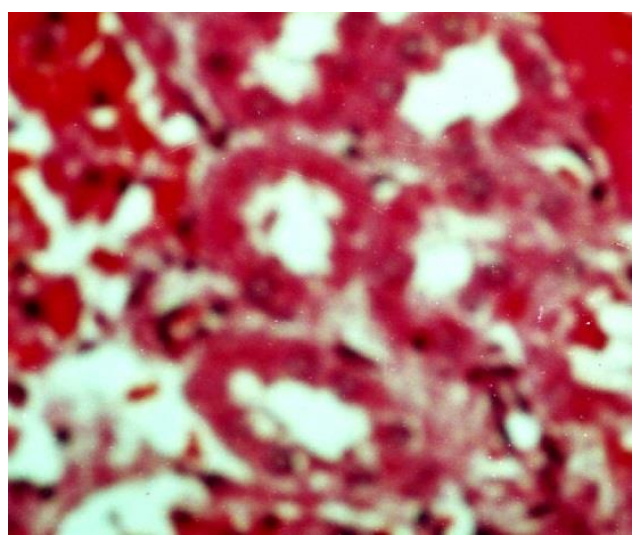

Figure 13: Kidney showing congestion of the glomerular tuft and interglomerular hemorrhage $(\mathrm{H} \& \mathrm{E} \times 300)$.

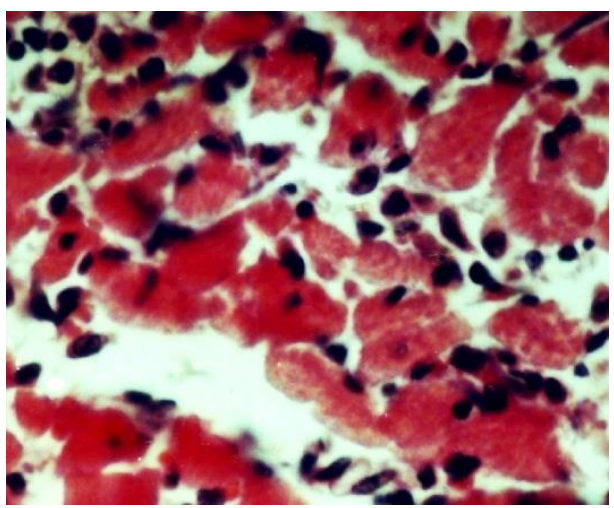

Figure 14: Heart showing intramuscular mononuclear infiltration (H\&E x 300). 


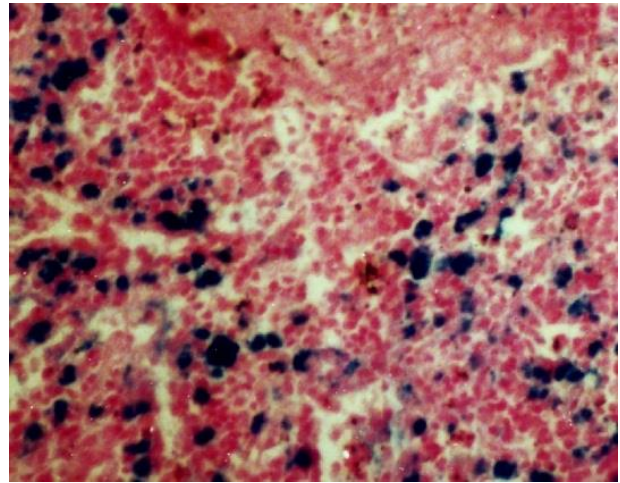

Figure 15: Showing hemosiderosis in the splenic tissue by prussian blue stain. (H\&E x 250).

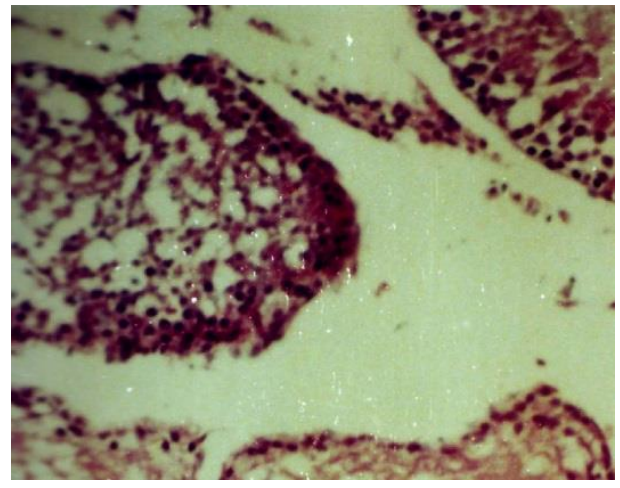

Figure 16: Testes showing edema and degeneration of seminiferous tubules with degenerated sperms $(\mathrm{H} \& \mathrm{E}$ x 300).

\section{DISCUSSION}

Human being now live in an environment in which at least 100,000 chemicals are prevalent and to which approximately, 100 new compounds are added each year. ${ }^{16}$ Benzene is an important industrial solvent and common pollutant which can develop aplastic anaemia and leukemia in exposed individuals.

In our study, the clastogenic effect caused by chronic exposure to air pollutants under investigations has been shown in (Tables 1 and Table 2) and (Figures 1-6). Benzene exposure resulted in high frequencies of chromosomal aberrations. The percentages of chromosomal aberrations in examined metaphase spread were $18 \%$ and $26 \%$ in the $2^{\text {nd }}$ and the $3^{\text {rd }}$ exposed groups in comparison to $8 \%$ in the control one. The structural and numerical aberrations in this study are shown in (Table 1) and (Figs 1-4) as gap, fragment, chromatid break, deletion, sticky, ring, end-to-end association, centromeric attenuation and polyploidy.

(Table 1) and (Figure 5 and Figure 6) summarized micronuclei formation due to exposure to air pollutant at benzene station. Micronuclei formation either in polychromatic erythrocyte (PCE) or normochromatic erythrocyte showed a higher record in benzene exposed group. In this respect, we have a good agreement with many authors, e.g. ${ }^{3,4,7}$ In an attempt to explain the mechanism of genotoxicity of benzene, ${ }^{17}$ demonstrated that during the peroxidase-mediated metabolism of phenol, (a metabolite of benzene) one or more potent inhibitors of enzyme top isomerase II are formed and the inhibition of this enzyme by benzene metabolites may play an important role in chromosomal aberrations as well as micronuclei formation due to benzene or its metabolites.

Data of the present study also showed that the lungs of benzene-exposed rats revealed congested blood vessels, perivascular hemorrhage and edema. The bronchioles showed hyperplasia and desquamation of the lining epithelium. Moreover, squamous metaplasia was also detected. These findings were in a partial agreement with. ${ }^{10}$

Histopathological examination revealed presence of mild degenerative changes of the hepatocytes manifested by vacuolar and hydropic degenerations. Moreover, focal areas of necrosis of the hepatocytes were also detected. The portal areas showed the presence of focal mononuclear infiltration. These findings were in a complete agreement with the results detected by ${ }^{8,10,11}$ Meanwhile, disagree with the results mentioned by ${ }^{9}$ who described preneoplastic changes in such cases of pollution.

Moreover, our results were agree with the results mentioned by ${ }^{18}$ who recorded increased ALT and AST with pathological alterations in liver and spleen of female mice exposed to nitrobenzene.

Our results revealed nephrotoxic effects confirmed by histopathological examination of the kidneys which revealed presence of degenerative changes of the renal tubules in the form of cloudy swelling or even desquamation of the epithelial cell lining the renal tubules. Moreover, hyaline casts were also seen in the renal tubules. These findings were in consistence with. ${ }^{19,10,20}$

Histopathologically, cardiotoxic effects were indicated by hyalinization of cardiac muscle cells with mononuclear infiltration. These findings were in a partial agreement with $^{21}$ spleen and testes also showed degenerative changes including hemosiderosis and edema and degenerated sperms, respectively.

It could be concluded that our results indicated many toxic effects due to benzene exposure which included genotoxicities and histotoxicities in the form of various degenerative changes in most vital organs like liver, kidneys, lungs, heart, spleen and testes. So in order to minimize the occurrence of such toxic effects of occupational exposure to benzene the following points should be put in considerations: i) continuous health monitoring of exposed workers through preplacement and 
periodic health examination. ii) Regular determination of benzene concentration in the working atmosphere is of utmost importance. In developed countries, the allowable work place level of benzene is $1 \mathrm{ppm}^{22}$

Funding: No funding sources

Conflict of interest: None declared

Ethical approval: The study was approved by the institutional Animal ethics committee

\section{REFERENCES}

1. USEPA. U.S. Environmental Protection Agency's Integrated Risk Information System (IRIS) for benzene. Available at http://www.epa.gov/ngispgmz/isis and the substance File List as of October. 1998;16.

2. Ruiz M, Augusta L, Vassallo J, Vigorito A, LorandMetze and Souza, C. Bone marrow morphology in patients with neutropenia due to chronic exposure to organic solvents (benzene): Early lesions. Pathol. Res. Pract. 1994;190:151-4.

3. Kalf G. Recent advances in the metabolism and toxicology of benzene. Crit. Rev. Toxicol. 1987; 18:141-59.

4. Ning H, Kado N, Kuzmicky P, Hsieh D. Benzeneinduced micronuclei formation in mouse fetal liver blood, peripheral blood and maternal bone marrow cells, Environ. Mol. Mutagen. 1991;18:1-5.

5. Sasiadek M. Non-random distribution of break point in the karyotypes of workers occupationally exposed to benzene. Environ. Health. Perspect. 1992;97:2557.

6. Eastmond D, Rupa D., Hasegawa L. Detection of hyperdiploidy and chromosome breakage in interphase human lymphocytes following exposure to the benzene metabolite hydroquinone using multicolor fluorscince in site hyperdization with DNA probes. Mutation Res. 1994;322:9-20.

7. Chen H, Eastmond D. Synergestic increase in chromosomal breakage within the euchromatin induced by an interaction of the benzene metabolites phenol and hydroquinone in mice. Carcinogenesis. 1995;16 (ISS8):1963-9.

8. Babany G, Bernuav J, Cailleux A, Cadranel J, Degott C, Erlinger S, Benhomou J. Sever monochlorobenzene-induced liver cellnecrosis. Gastroenterology. 1991;101:1734-6.

9. Hartley W, Thiyagarajah A, Major S, Fields N, Broxson M. Evaluation of the histopathological and developmental effects of hydro-carbon mixtures in the Japanese medaka fish. Toxicologist. 1996;30(1pt):8.
10. Morgan O, Mahler J, Wilson R, Morrman M, Price $\mathrm{H}$, O'Connor. Toxicity of divinyl benzene-55 for B6C3 F1 mice in a two week inhalation study. Fundam. Appl. Toxicol. 1977;39:89-100.

11. Szymanska JA. Hepatotoxicity of brominated benzenes: Relationship between chemical structure and hepatotoxic effects in acute intoxication of mice. Arch. Toxicol. 1998;72:97-103.

12. Giri A, Talukder G, Sharma A. Sister chromatide exchange induced by Metanil Yellow and nitrate singly and in combination in vivo on mice. Cancer Lett. 1986;31:299-303.

13. Schmid W. The micronucleus test for cytogenetic analsysis chemical Mutagens: principles and methods for their detection. Hollaender (Ed.). New York, London: Plenum Press; 1976; 4: 31-53.

14. Drury R, Wallington E. Carleton's Hisological Technique, 5th Ed. London, New York, Toronto: Oxford Univ. Press; 1980.

15. Mallory FB. Pathological Technique. Philadelphia: W.B. Sounders Co.; 1938: 137.

16. Li S. Reproductive Toxicology. China: Reproductive Toxicology; 1993: 63-71.

17. Eastmond D. Chromosomal mechanisms in environmental carcinogenesis, FEDRIP DATA BASE, National Technological Information Service (NTIS) 1995.

18. Burn L, Bradley S, White K, McCay J, Fuchs B, Stern M, Brown R, Musgrove D, Holsapple M, Kuster M. Immunotoxicology of nitrobenzene in female B6C3 F1 mice. Drug Chem. Toxicol. 1994;17:271-315.

19. Den-Besten C, Vet JJ, Besselink HT, Kiel GS, van Berkel BJ, Beems R, van Bladeren PJ. The liver, kidney, and thyroid toxicity of chlorinated benzenes. Toxicol Appl Pharmacol. 1991;111:69-81.

20. Peters MM, Jones TW, Monks TJ, Lau SS. Cytotoxicity and cell-proliferation induced by the nephrocarcinogen hydroquinone and its nephrotoxic metabolite 2,3,5-(tris-glutathion-S-yl)hydroquinone. Carcinogenesis. 1997; 18:2393-401.

21. Ektachem. Ektachem Clinical Chemistry, Creatine kinase multiple point rate test. 1995. Publication No. MP2-42. CAT No. 8482085.

22. Bogadi-Sare A. Early detection of the toxic effects of benzene onthe hematopoietic system- the imperative of modern occupational medicine. Arch Hig. Rada. Toksikol. 1992;43:271-82.

doi:10.5455/2319-2003.ijbcp20140218

Cite this article as: Abousalem M, Elgerwi A, ElMashad AB. Genotoxic and histotoxic effects of air pollutants at a benzene station on albino rats. Int $\mathbf{J}$ Basic Clin Pharmacol 2014;3:144-50. 